\title{
Ergonomic assessment methodologies in manual handling of loads - opportunities in organizations
}

\author{
Claudia Pires ${ }^{\mathrm{a}}$ \\ ${ }^{a}$ CATIM - Centro de Apoio Tecnológico à Indústria Metalomecânica, Rua dos Plátanos 197, 4100-414 Porto, \\ Portugal.claudia.pires@catim.pt
}

\begin{abstract}
The present study was developed based on the analysis of workplaces in the engineering industry, particularly in automotive companies. The main objectives of the study were to evaluate the activities present in the workplace concerning manual handling, using assessment methodologies NIOSH Ergonomic Equation [1] and Manual Material Handling [2], present in ISO 11228 [3-4], and to consider the possibility of developing musculoskeletal injuries associated with these activities, an issue of great concern in all industrial sectors. Similarly, it was also shown the suitability of each method to the task concerned. The study was conducted in three steps. The first step was to collect images and information about the target tasks. As a second step proceeded to the analysis, determining the method to use and to evaluate activities. Finally, we found the results obtained and acted on accordingly. With the study observed situations considered urgent action, according to the methodologies used, and proceeded to develop solutions in order to solve the problems identified, eliminating and / or minimizing embarrassing situations and harmful to employees.
\end{abstract}

Keywords: ergonomics, prevention, musculoskeletal injuries, assessment methodologies

\section{Introduction}

Currently, there is a growing modernization, as a necessity to exceed targets and goals in order to achieve the desired success. However, in a scenario where technology and innovation-are the words of the day, it becomes difficult to observe essential features, but with low visibility and considered to be secondary issues in most organizations, such as the development of pathologies and injuries associated with manual handling. It is public knowledge some numbers regarding this situation, but it is know that not all cases are notified and given that some lesions appear until years later, there is only approximate values, and it is not possible to present an accurate representation of reality. Before such a scenario companies faced with an unavoidable decision, the need of a paradigm shift in organizations. It is not possible a sustained growth only with the restricted view of the results of production, we must go further and an investment is required in the main and most important existing resource in an organization, people. Thus we should come up with solutions whose aim is to improve working conditions, welfare, safety and health, and thereby to contribute to the elimination / minimization of the potential risks of musculoskeletal disorders.

Although some companies already have the consciousness that is necessary to act can sometimes arise barriers that hinder the decision, eg. [5]: difficulty to assess the tasks due to the existence of various methods, that even with advantages, presents also limitations and that sometimes are only used effectively by "capable" people (depending on the experience and sensitivity of the evaluator), difficulty in determining "what" and "how," including preventive measures or corrective and design of workplaces (which parameters to consider); costs associated with implementing the necessary changes, difficulty in making the return on investment with these measures, i.e., determine the cost / benefit (you 
can not always translate to numbers, mainly in the short term).

The study's main goal was to evaluate two different workplaces in two engineering companies. We identified three tasks at the first position (carriage parts, supply of machine components and disposal of parts after machining) and at the second position four tasks (placing the piece on the table, machining, piece rotation and removal of the part).

For the analysis of the tasks, it was observed the adoption of awkward postures while handling loads, which further enhances the development of lesions.

It is necessary to reinforce the value of such studies, because it can be seen daily and it is often neglected perhaps due to multi-simplicity of knowledge necessary for their achievement and the fact that the dangerous situation is not promptly detected and the lesions appear later.

\section{Material and methods}

Many tasks submit employees to manual handling of loads, but the definition of higher risk activities, the actual risk of each situation and also the methodology used difficult the performance of large companies. The question that arises is: [5] "Does the employee carries out its activity within acceptable limits or is there any possibility of developing musculoskeletal disorders?"

The famous quote by Archimedes at the question: "How much weight you can lift a man?" where he answers: "It depends, give me a good handle and a head support that will lift the world" reflects the difficulty in determining the ideal weight and on what terms it can be done.

The study took place in two companies contemplating two workplaces whose tasks involve different requests, posture and strength.

In order to evaluate and determine the risk associated with manual handling of load was applied the following methodologies:

- NIOSH equation [1] (National Institute of Occupational Safety and Health) procedure of the manual handling of loads.- It should be noted that this method does not include tasks that involve movement of the workman;

- Manual Material Handling [2]: method for assessing manual handling tasks including assessing which tasks allows the employee to travel (push, pull and carry). However, this method presents a higher degree of difficulty as it is necessary to consult a large number of tables, as well as the need for interpolation to the values that are not tabulated.

The methodology NIOSH is based on Eq. (1) [6]:

$\mathrm{RWL}=\mathrm{LC} \times \mathrm{HM} \times \mathrm{VM} \times \mathrm{DM} \times \mathrm{AM} \times \mathrm{CM} \times \mathrm{FM}(1)$

Where RWL is the recommended weight limit, LC is the constant load, HM horizontal multiplier, VM vertical multiplier, DM distance multiplier, AM asymmetry multiplier, $\mathrm{CM}$ coupling multiplier and FM frequency multiplier.

On the other hand, the Manual Material Handling is based on the look-up tables with optimal values depending on a set of pre-established parameters. From this analysis withdraw or interpolate values in order to obtain the recommended weight under certain conditions.

The NIOSH method is described in ISO 112281:2003 - Ergonomics - Manual handling - Part 1: Lifting and carrying. While the methodology Manual Material Handling is described in ISO 11228-2:2007 - Ergonomics - Manual handling - Part 2: Pushing and pulling.

In both methods, we did a comparison of the recommended weights with the value of load handled and obtained an $\mathrm{R}$ value, which reflects the level of risk associated with the activity. The criteria are set out in Table 1 [2].

Table 1 - Criteria used to analyze the level of risk

\begin{tabular}{|l|l|l|}
\hline Level & Score & Interpretation of Results \\
\hline 1 & $\mathrm{R}<1$ & $\begin{array}{l}\text { The weight handled do not present } \\
\text { risk of musculoskeletal injury to } \\
\text { workers if not repeated for long } \\
\text { periods }\end{array}$ \\
\hline 2 & $\mathrm{R}=1$ & $\begin{array}{l}\text { The weight manipulated can be } \\
\text { physiologically harmful. Some } \\
\text { workers may suffer from } \\
\text { musculoskeletal disorders if exposed } \\
\text { to this situation for a long period }\end{array}$ \\
\hline 3 & $\mathrm{R}>1$ & $\begin{array}{l}\text { The situation presents a high risk. } \\
\text { implemented quickly }\end{array}$ \\
\hline
\end{tabular}




\section{Results and discussion}

In this study we observed two distinct workplaces designated W.T.1 and W.T.2 and evaluated all tasks present in the workplaces. However, this study will only present situations identified as urgent, after the application of methodologies and measures.

To evaluate the tasks we used NIOSH method for tasks without moving the collaborator and for other situations we used the methodology Manual Material Handling.

\section{W.T.1}

Task evaluated: Placement / removal of parts on the machine, using accessories such as blades and / or buckets (weight handled between 15 to $30 \mathrm{~kg}$ ) (Fig. 1) [7].

Description of situations to consider:

- Location of retention basins increases the distance from the operator to the machine. This positioning of basins is due to the presence of the collector bucket on the front. This concept requires the adoption of incorrect movements including flexion, rotation and tilt of the trunk, associated with load;

- Upper cylindrical structure stands apart from the operator and provides a narrow opening for placement of parts, which preclude the use of the existing mechanical structure;

- Design of the collecting structure for pieces which has a slope in order to these pieces fall into the bucket that is in front of the machine. This conception requires the adoption of demanding postures, including flexion and trunk rotation.

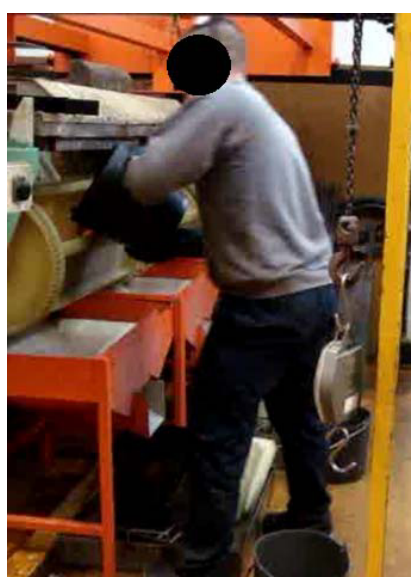

Fig. 1 - Supply of parts in the machine
Risk Assessment: $\mathrm{R}>1$ - The situation presents a risk. Remedial measures should be implemented quickly.

Actions to improve:

- Changing the location of the retention basin to the bottom of the machine (Fig. 2). Putting wheels in the retention basin to allow easy and convenient travel of the bucket collectors; - Changing the structure of collecting parts so that they fall vertically. (Fig. 2);

- Increase the opening of the upper cylindrical structure, which allows the manipulation by mechanical means (Fig. 3).

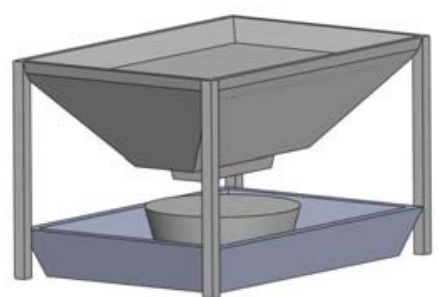

Fig. 2 - Collecting vertical structure and retention basin with bearing (not visible in the picture)

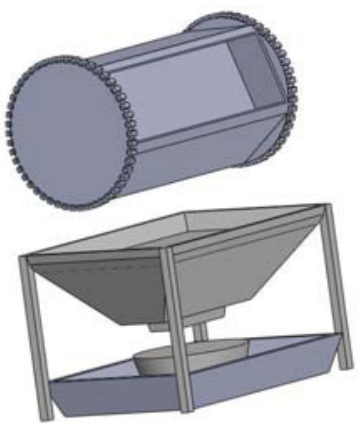

Fig. 3 - Opening of the upper structure

W.T.1 (continued)

Task evaluated: Transport of buckets (weighing between 25 to $30 \mathrm{~kg}$ ) (Fig. 4):

Description of situations to consider:

- 6 meters distance traveled between the warehouse and the machine with two buckets of considerable weight;

- Adoption of awkward postures during load handling. 


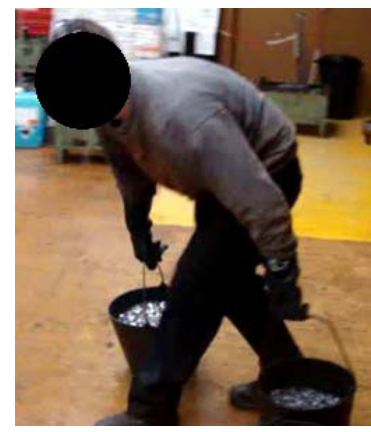

Fig. 4 - Transport buckets

Risk Assessment: $\mathrm{R}>1$ - The situation presents a risk. Correction measures should be implemented quickly.

Actions to improve:

- Introduction of a conveyer;

- Implementation of cranes or rolling bridges;

- Training on the adoption of correct posture when handling loads.

\section{W.T.2}

Task assessed: daily handling of components for automobile engines with approximately $50 \mathrm{~kg}$ (Fig. 5)

Description of situations to consider:

- Transport of the component from the ground to the desk encourages the development of lesions by the combined weight manipulated the posture adopted and the vertical distance traveled;

- Chipping of the six sides of the piece forces you to tilt and rotate the piece, which leads to adoption of demanding postures, such as upper limb extension with load and severe flexion of the neck;

- Use of a drill to work the smaller holes and a flashlight to final inspection.

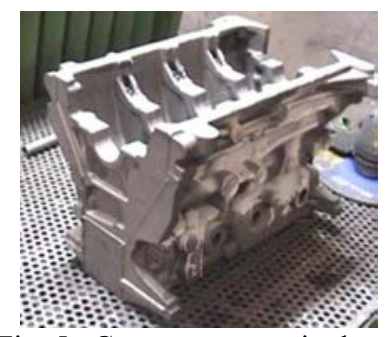

Fig. 5 -Component manipulated
Risk Assessment: R $>1$ - The situation presents a risk. Correction measures should be implemented quickly.

Actions to improve:

- Introduction of a rotary table (with the same rotation axis) which also allows an inclination of 60 degrees in order to eliminate the manual handling of the block during the grinding and the use of drill and minimize awkward postures (neck and wrists), witnessed during this tasks (Fig. 6 and 7);

- Introduction of the crane in order to eliminate the manual handling of loads during transportation of the piece from the ground to the table and the $180^{\circ}$ rotation of the piece to work in the bottom of it;

- The repositioning of the tools (drill and flashlight), to the top front in order to achieve better organization of the workplace, satisfaction of either hand and minimizing the effect of the weight of the tools.

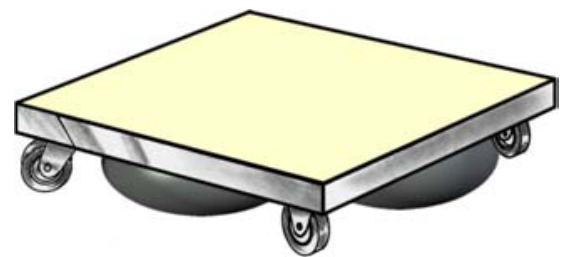

Fig. 6 -Example of rotary table with air bag filling

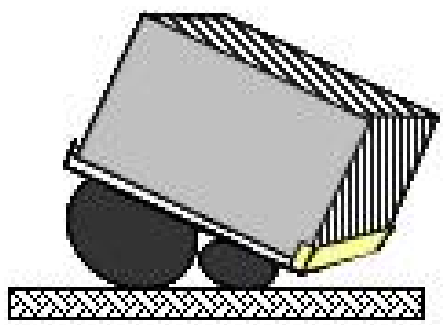

Fig. 7 -Possibility to tilt the table

\section{Conclusion}

From the application of ergonomic assessment methodologies it was possible to identify the embarrassing situations and assess the risks inherent to the tasks. Thus, from the knowledge of the critical situations, we acted in accordance with corrective measures, which showed substantial benefits to the companies concerned. 
Some measures are of low investment, eg. training on the adoption of correct postures and movements during manual handling and use of mechanical aids. However, others have a higher cost, but with obvious advantages, including the redesign of workplaces (machinery and equipment).

It was found after implementation of these solutions, a visible improvement in the postures adopted and the elimination of embarrassing situations, such as bending, trunk rotation and manipulation of excessive weight.

It is considered that the suggested measures contribute positively to the elimination / minimization of musculoskeletal injuries associated with the activities studied.

We can add that the actions implemented are reflected in the economic health of the company (due to reduction of direct and indirect costs) and forward them to the successful adoption of best practices minimizing costs.

\section{References}

[1] Applications manual for the revised NIOSH Lifting Equation. CDC, NIOSH, Cincinnati, OH 45226, USA, 1994

[2] Mital, A., Nicholson, A.S., Ayoub, M.M. A Guide to Manual Materials Handling, 2nd edition, Taylor and Francis London, Washington, DC, 1997

[3] ISO 11228-1:2003 - Ergonomics - Manual handling — Part 1: Lifting and carrying

[4] ISO 11228-2:2007 - Ergonomics - Manual handling - Part 2: Pushing and pulling

[5] Pires, Claudia. Movimentação Manual de Cargas: Oportunidades de Sucesso (2008), Internacional Symposium on Occupational Safety and Hygiene. Guimarães, Portugal

[6] Waters, T.R.; Anderson, V.; Garg, A.; Fine, L.J. Revised NIOSH equation for the design and evaluation of manual lifting tasks. Ergonomics vol.36, n.7, p. 749-776

[7] Pires, Claudia e Lima, Filipa. A Contribuição da Ergonomia na Segurança de Máquinas e Equipamentos (2011), Internacional Symposium on Occupational Safety and Hygiene. Guimarães, Portugal

[8] Pires, Claudia. Ergonomia na Prevenção de Lesões MúsculoEsqueléticas Relacionadas com o Trabalho (2009), Internacional Symposium on Occupational Safety and Hygiene. Guimarães, Portugal 